\title{
Intraductal tubulopapillary neoplasm of the pancreas diagnosed by endoscopic ultrasonography-guided fine needle aspiration
}

A 68-year-old man with chronic alcoholrelated pancreatitis and chronic nephropathy requiring dialysis was admitted to the hospital because of a 3-day history of upper abdominal pain. Laboratory tests revealed slightly elevated C-reactive protein with normal amylase and liver function test results. Computed tomography scan of the abdomen showed pancreatic calcifications and a cystic lesion in the head/neck of the pancreas. Subsequent endoscopic ultrasound (EUS) showed a multicystic lesion ( $\triangleright$ Fig. 1 ) with a dilated main pancreatic duct and a suspected solid lesion (> Fig.2). EUS-guided fine needle aspiration (FNA) of the suspected solid lesion in the main pancreatic duct was performed. Histopathology showed tubulopapillary structures with cylindrical cells and low grade dysplasia ( $\vee$ Fig. 3, - Video 1). There were no signs of mucin on periodic acid-Schiff and Alcian blue staining. On immunohistochemistry, the lesion was positive for CK7, CDX2 and MUC-1, and there was focal MUC6 reaction but only very few MUC5AC positive cells. The findings were consistent with an intraductal tubulopapillary neoplasm (ITPN). The patient was considered unfit for surgical treatment, and 6 months following the diagnosis he is alive without signs of disseminated disease.

ITPN is relatively rare, accounting for approximately $3 \%$ of all resected pancreatic intraductal neoplasms [1]. It may be radiologically indistinguishable from intraductal papillary mucinous neoplasm (IPMN). The diagnosis is made histologically, as ITPNs exhibit a tubular/cribriform growth with only minimal luminal/ intracellular mucin, whereas IPMNs show a papillary growth pattern [2]. On immunohistochemistry, IPMNs, but not ITPNs, are MUC5AC positive [3]. Although treatment of both tumors is similar, the prognosis of patients with ITPN is typically better than that for IPMN. This might be a relevant consideration when deciding

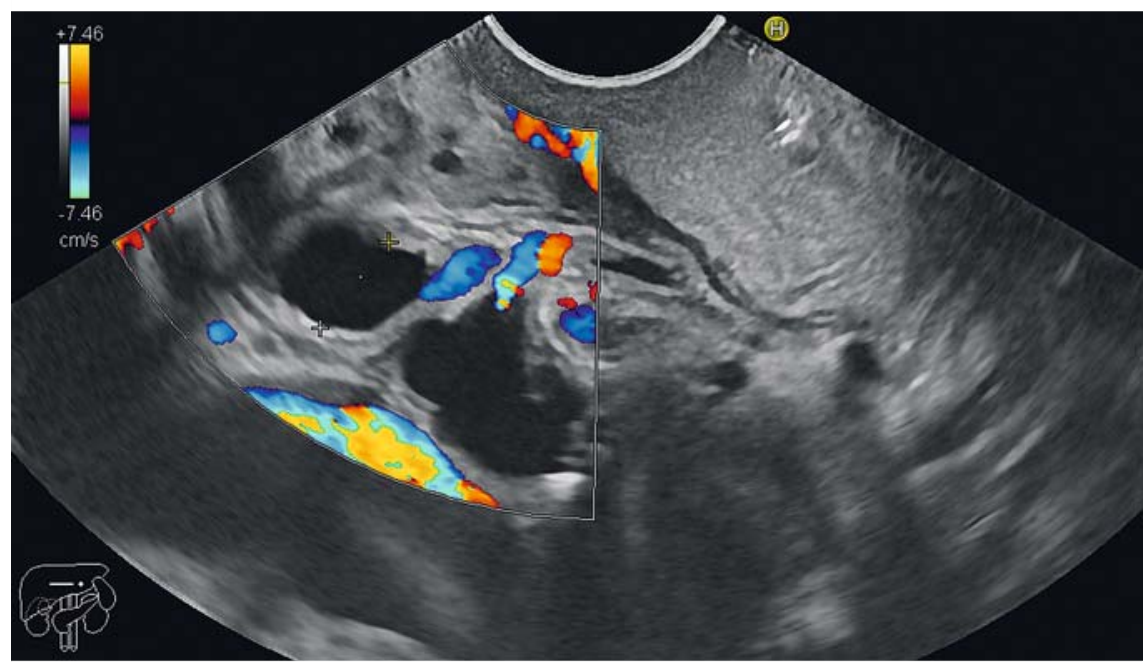

- Fig. 1 Endoscopic ultrasound scan of the head and neck of the pancreas showing a multicystic lesion. The patient was a 68-year-old man with chronic alcohol-related pancreatitis and chronic nephropathy.
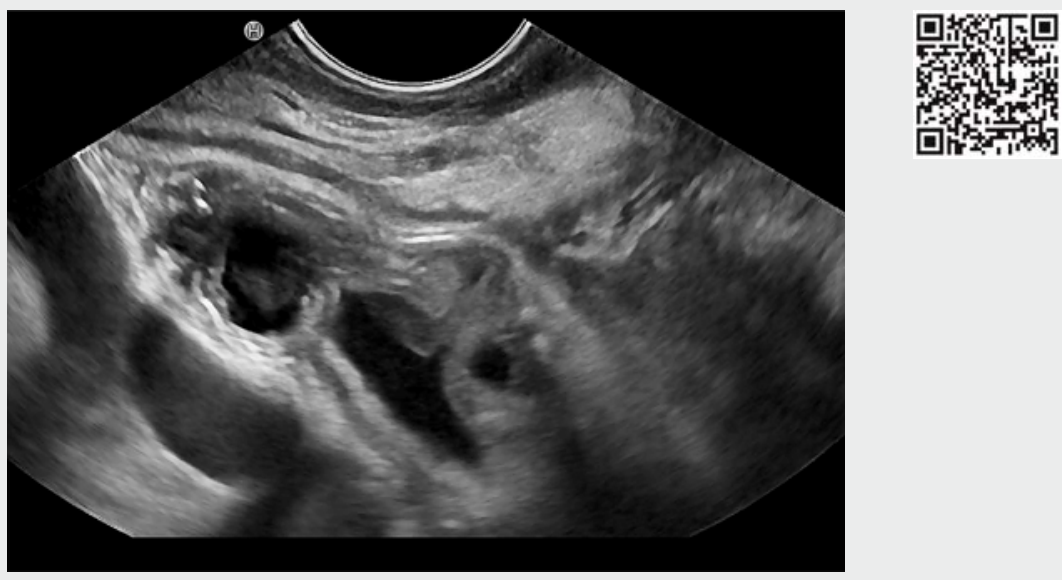

Video 1 Endoscopic ultrasound scan of a pancreatic lesion, ultimately diagnosed following endoscopic ultrasound-guided fine needle aspiration (EUS-FNA) as an intraductal tubulopapillary neoplasm (ITPN).

the follow-up of patients, particularly those who are poor surgical candidates. To our knowledge, ours is one of the very few published cases on the appearance of ITPN on EUS and on the utility of EUS-FNA in the differential diagnosis.
Endoscopy_UCTN_Code_CCL_1AF_2AZ_3AB

Competing interests 


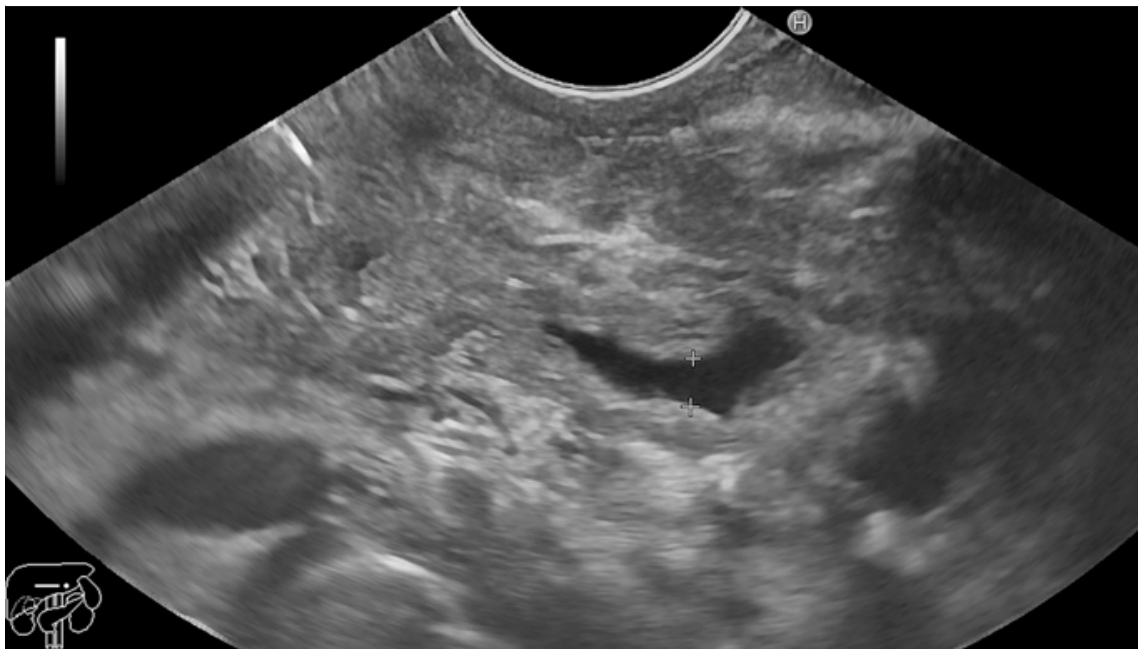

Fig. 2 Endoscopic ultrasound scan of the neck/body of the pancreas showing a dilated main pancreatic duct with a suspected solid lesion.

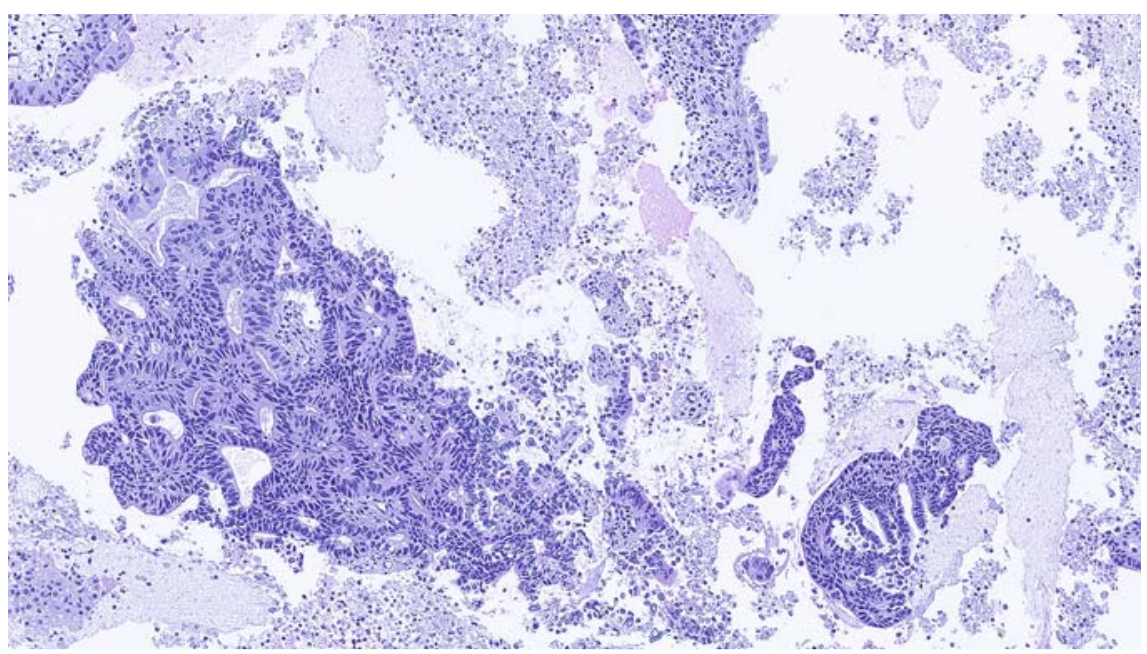

- Fig. 3 Histopathological appearance of tissue material, obtained from the intraductal solid component of the cystic lesion by means of endoscopic ultrasound-guided fine needle aspiration (EUS-FNA), showing tubulopapillary structures with cylindrical cells and low grade dysplasia (hematoxylin and eosin [H\&E]).

Bojan Kovacevic ${ }^{1}$, Patricia Latorre Añó ${ }^{1}$, Anders Toxværd ${ }^{2}$, Peter Vilmann' ${ }^{1}$, Evangelos Kalaitzakis ${ }^{1}$

1 Endoscopy Unit, Digestive Disease Center, Copenhagen University Hospital Herlev, University of Copenhagen, Copenhagen, Denmark

2 Department of Pathology, Digestive Disease Center, Copenhagen University Hospital Herlev, University of Copenhagen, Copenhagen, Denmark
Endoscopy Unit, Digestive Disease Center, Copenhagen University Hospital Herlev, University of Copenhagen, 2730 Herlev, Denmark

Fax: +45-38-684009

kalvag@hotmail.com
Evangelos Kalaitzakis, MD, PhD, MSc

\section{References}

[1] Yamaguchi H, Shimizu M, Ban S et al. Intraductal tubulopapillary neoplasms of the pancreas distinct from pancreatic intraepithelial neoplasia and intraductal papillary mucinous neoplasms. Am J Surg Pathol 2009; 33: $1164-1172$

[2] Guan H, Gurda G, Lennon AM et al. Intraductal tubulopapillary neoplasm of the pancreas on fine needle aspiration: case report with differential diagnosis. Diagn Cytopathol 2014; 42: $156-160$

[3] Basturk O, Coban I, Adsay NV. Pancreatic cysts: Pathologic classification, differential diagnosis, and clinical implications. Arch Pathol Lab Med 2009; 133: 423-438

\section{Bibliography}

DOI https://doi.org/10.1055/s-0043-115892

Published online: 3.8.2017

Endoscopy 2017; 49: E266-E267

(c) Georg Thieme Verlag KG

Stuttgart · New York

ISSN 0013-726X

\section{ENDOSCOPY E-VIDEOS}

https:/|eref.thieme.de/e-videos

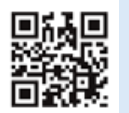

Endoscopy E-Videos is a free access online section, reporting on interesting cases and new techniques in gastroenterological endoscopy. All papers include a high quality video and all contributions are freely accessible online.

This section has its own submission website at

https://mc.manuscriptcentral.com/e-videos

\section{CORRECTION}

Kovacevic B, Latorre Añó P, Toxværd $A$ et al. Intraductal tubulopapillary neoplasm of the pancreas diagnosed by endoscopic ultrasonographyguided fine needle aspiration. Endoscopy 2017, doi:10.1055/s-0043115892

The name of the author Evangelos Kalaitzakis was corrected from “Evangelos Kalaizakis” to "Evangelos Kalaitzakis”. 